\title{
Age at menarche and prevention of hypertension through lifestyle in young Chinese adult women: result from project ELEFANT
}

Liqiong Guo ${ }^{1 *+} \mathbb{B}$, Cheng Peng ${ }^{2+}$, Hui Xu ${ }^{1,3+}$, Ander Wilson ${ }^{4}$, Peng-hui Li ${ }^{5}$, Hao Wang ${ }^{6}$, Hongbin Liu 6 , Lilin Shen ${ }^{6}$, Xi Chen ${ }^{1}$, Xiuying $\mathrm{Qi}^{3}$, Nai-jun Tang ${ }^{1}$, Timothy M. Barrow ${ }^{7}$ and Hyang-Min Byun ${ }^{8}$

\begin{abstract}
Background: Early and late age at menarche are associated with risk of hypertension, but little is known whether modifiable lifestyle can reduce this risk.

Methods: Our study leverages 60,135 healthy young Chinese women from the Environmental and LifEstyle FActors iN metabolic health throughout life-course Trajectories (ELEFANT) study. Menarche age and lifestyle factors were assessed by self-reported questionnaires and hypertension was diagnosed by physicians. We estimated the odds ratios (ORs) of hypertension associated with menarche age using multivariable logistic regression. We further investigated whether modifiable lifestyles (body mass index, BMl; psychological stress; passive smoking; and imbalanced diet) increased risk in joint analyses.

Results: The association between age at menarche and hypertension was U-shaped, with age $\leq 12$ at menarche giving the highest $\mathrm{OR}(1.46,95 \%$ confidence interval $[\mathrm{Cl}], 1.27-1.69)$ and $\geq 16$ the second highest $(\mathrm{OR}=1.36,95 \%$ $\mathrm{Cl}=1.15-1.62$ ). Simultaneous analysis of lifestyle risk factors and age of menarche showed that having one or more modifiable risk factors increased the menarche age-hypertension association. The risk of hypertension among participants with menarche age $\leq 12$ decreased from OR $13.21(95 \% \mathrm{Cl}=5.17-29.36)$ with four high-risk lifestyle factors to $12.36(95 \% \mathrm{Cl}=9.51-16.05)$ with three high-risk factors, $5.24(95 \% \mathrm{Cl}=4.11-6.69)$ with two, and 2.76 (95\% Cl=2.09-3.60) with one, in comparison to individuals with no high-risk lifestyle factors and menarche age 14.

Conclusions: Our results suggest that modification of lifestyle, including maintenance of normal weight and a balanced diet, are associated with substantially reduce the risk of hypertension in high-risk individuals.

Plain English summary: Early and late age at menarche are risk factors for the development of hypertension in Western populations, and there is limited evidence that this is also true of Chinese populations. Targeted prevention of hypertension in vulnerable populations would be highly beneficial in efforts to reduce the incidence of cardiovascular disease, but it is not currently known whether lifestyle intervention could reduce hypertension risk. In this study, we analysed the risk of hypertension by age at menarche and four modifiable lifestyle factors (BMI, diet, psychological stress, and smoking tobacco) in a cohort of 60,135 young adult Chinese women (mean age 29). We identified that early and late age at menarche are associated with increased risk of hypertension in young Chinese (Continued on next page)
\end{abstract}

\footnotetext{
* Correspondence: yingqidao@163.com; guoliqiong@tmu.edu.cn

'Liqiong Guo, Cheng Peng and Hui Xu contributed equally to this work.

'Department of Occupational \& Environmental Health, School of Public

Health, Tianjin Medical University, 22nd Qixiangtai Road, Heping District,

Tianjin 300070, China

Full list of author information is available at the end of the article
}

(c) The Author(s). 2018 Open Access This article is distributed under the terms of the Creative Commons Attribution 4.0 International License (http://creativecommons.org/licenses/by/4.0/), which permits unrestricted use, distribution, and reproduction in any medium, provided you give appropriate credit to the original author(s) and the source, provide a link to the Creative Commons license, and indicate if changes were made. The Creative Commons Public Domain Dedication waiver (http://creativecommons.org/publicdomain/zero/1.0/) applies to the data made available in this article, unless otherwise stated. 


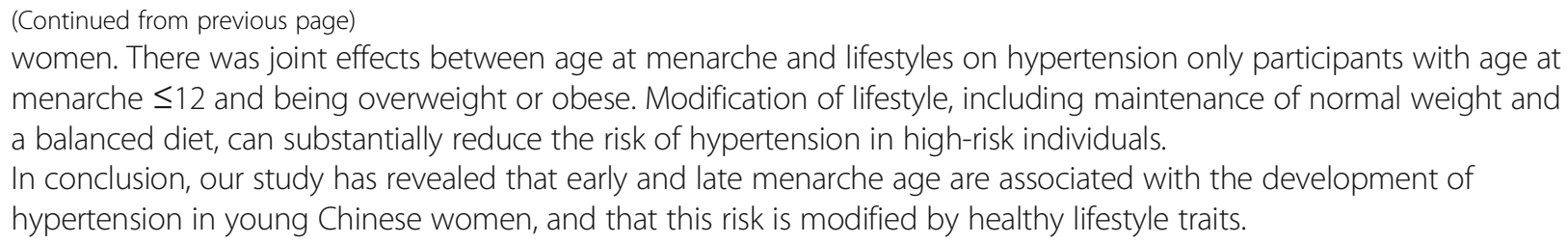

Keywords: Menarche, Hypertension, Lifestyle

\section{Background}

Age at menarche is determined by genetic profile, hormonal levels, and external factors such as exposure to environmental chemicals, diet, physical activity, and smoking [1-4]. Early and late menarche age are known to be risk factors associated with adult onset diseases, including ischaemic heart disease, and hypertension, and may in part explain sex differences in the risk of cardiovascular disease (CVD) [5-8]. Although hypertension is most prevalent in elderly populations and displays increased risk with ageing, there remains a considerable number of hypertension cases among young adults independent of familial history of hypertension $[9,10]$. The early prevention of hypertension in vulnerable individuals, such as young adult women with early or late age at menarche, is cardinal. Healthy lifestyle has been suggested as a long-term approach for the prevention of diseases including hypertension [11], and may ameliorate the increased risk associated with early or late age at menarche.

In this study, we assessed the risk of hypertension by menarche age and by level of four modifiable lifestyle factors in young adult Chinese women. The four modifiable factors were: body mass index (BMI); psychological stress; smoking status; and imbalanced diet. By estimating the synergistic association of lifestyle factors and age of menarche on hypertension risk, we demonstrate the high-impact potential for intervention to reduce incidence in high-risk individuals.

\section{Methods}

\section{The ELEFANT participants}

Project Environmental and LifEstyle FActors iN metabolic health throughout life-course Trajectories (ELEFANT) is a population study comprising three age-based cohorts: Baby ELEFANT (mean age 0); Young ELEFANT (mean age 29); and Elderly ELEFANT (mean age 69) [12]. All participants resided in Tianjin city, China (area: $11760 \mathrm{~km}^{2}$, population: 156,200,000 in 2016) at the time of recruitment. In this study, we utilised the Young ELEFANT cohort, which is a cross-sectional study for which data collection began in 2014. The total number of participants within Young ELEFANT is 124,286 (50\% male). The participants are living in Tianjin city who visited clinics in Tianjin between 2014 and 2015 for regular check-ups. Basic demographic and clinical characteristics were collected through questionnaires, which measured socioeconomic and lifestyle data such as education level, occupation, smoking status, drinking behaviour, psychological stress, and dietary habits during the period 2014 to 2015 . Reproductive characteristics (age at menarche, menstrual cycle length, menstrual bleeding duration, and dysmenorrhea), personal history of disease, familial history of disease, and medication use were also collected (Table 1). The protocol of this study was approved by the Institutional Review Board of the Tianjin Medical University and the procedures followed were in accordance with institutional guidelines. Participants gave written informed consent prior to participation in the study.

\section{Sampling process and eligibility criteria}

The selection process for female participants within the Young ELEFANT cohort is described in Fig. 1. We excluded participants with history of cancer $(n=78)$, heart disease $(n=78)$, birth defect $(n=93)$, participants aged $>40$ years $(n=1046)$, and those with age at menarche of $<8$ years $(n=5)$ and $>20$ years $(n=140)$. We also excluded participants with missing data $(n=568)$. Following these exclusions, 60,135 participants aged 24-40 were included in the final analysis for this study.

\section{Ascertainment of questionnaire data}

Self-reported menarche age from questionnaire data for each participant were categorised as $\leq 12,13,14,15$, and $\geq 16$ years. Median age of menarche in China is 14-year-old and was subsequently used as the reference age in our analysis [13].

Psychological stress was estimated through structured questionnaires to determine whether participants experienced work-related stress, social stress, or financial stress. The Occupational Stress Indicator (OSI) [14] and the Perceived Stress Scale (PSS-10) [15] were used. The PSS-10 is a self-report instrument which measures the perception of stress and ability to cope, such as how unpredictable, uncontrollable and overloaded the individual perceives their life to be. The OSI assess occupational 
Table 1 Basic characteristics of the study population by age at menarche

\begin{tabular}{|c|c|c|c|c|c|c|}
\hline & Age at menarche & & & & & \\
\hline \multirow[t]{2}{*}{ Variables } & Total $(n=60,135)$ & $\leq 12$ & 13 & 14 & 15 & $\geq 16$ \\
\hline & & $(n=9347)$ & $(n=13,476)$ & $(n=23,184)$ & $(n=9017)$ & $(n=5108)$ \\
\hline Age at enrolment, mean (SD) & $29(4)$ & $30(4)$ & $30(40)$ & $29(4)$ & $29(4)$ & $30(4)$ \\
\hline BMI $\left(\mathrm{kg} / \mathrm{m}^{2}\right)$, mean $(\mathrm{SD})$ & $23(4)$ & $23(4)$ & $23(4)$ & $22(4)$ & $22(4)$ & $22(4)$ \\
\hline Overweight (BMI 24-28), n (\%) & $11,613(19)$ & $2060(18)$ & $2652(23)$ & $4319(37)$ & $1621(14)$ & $961(8)$ \\
\hline Obese (BMI $\geq 28), n(\%)$ & $4244(7)$ & $894(21)$ & $973(23)$ & $1474(35)$ & $580(14)$ & $323(8)$ \\
\hline SBP $(m m H g), n(\%)$ & $112(10)$ & $112(11)$ & $112(10)$ & $112(10)$ & $112(10)$ & $112(10)$ \\
\hline $\mathrm{DBP}(\mathrm{mmHg}), n(\%)$ & $72(8)$ & $72(9)$ & $72(8)$ & $72(8)$ & $72(8)$ & $72(8)$ \\
\hline Alcohol drinker, $n(\%)$ & $4237(7)$ & $1388(33)$ & $1022(24)$ & $988(23)$ & $450(11)$ & $389(9)$ \\
\hline Active smoker, $n(\%)$ & $774(1)$ & $241(31)$ & $182(24)$ & $167(22)$ & $101(13)$ & $83(11)$ \\
\hline Passive smoking, $n(\%)$ & $14,892(25)$ & $4103(28)$ & $3622(24)$ & $3683(25)$ & $1926(13)$ & $1558(10)$ \\
\hline Imbalanced diet, $n$ (\%) & $1350(2)$ & $274(20)$ & $327(24)$ & $359(27)$ & $181(13)$ & $209(15)$ \\
\hline \multicolumn{7}{|l|}{ Education (years) } \\
\hline$\leq 9, n(\%)$ & $22,537(37)$ & $1466(7)$ & $4698(21)$ & $10,159(45)$ & $4122(18)$ & $2092(9)$ \\
\hline $10 \sim 15, n(\%)$ & $11,372(19)$ & $1507(13)$ & $2518(22)$ & $4540(40)$ & $1696(15)$ & $1111(10)$ \\
\hline$\geq 16, n(\%)$ & $26,181(44)$ & $6362(24)$ & $6250(24)$ & $8473(32)$ & $3194(12)$ & $1902(7)$ \\
\hline \multicolumn{7}{|l|}{ Occupation } \\
\hline Manual work, n (\%) & $43,286(73)$ & $4454(10)$ & $9250(21)$ & $18,632(43)$ & $7149(17)$ & $3801(9)$ \\
\hline Non-manual work, n (\%) & $15,178(26)$ & $4294(28)$ & $3841(25)$ & $4170(27)$ & $1709(11)$ & $1164(8)$ \\
\hline Unemployed, n (\%) & $883(2)$ & $298(34)$ & $200(23)$ & $213(24)$ & $94(11)$ & $78(9)$ \\
\hline \multicolumn{7}{|l|}{ Region } \\
\hline Rural, $n$ (\%) & $39,233(65)$ & $3242(8)$ & $8409(21)$ & $17,356(44)$ & $6662(17)$ & $3564(9)$ \\
\hline Urban, $n(\%)$ & $20,911(35)$ & $6105(29)$ & $5076(24)$ & $5830(28)$ & $2356(11)$ & $1544(7)$ \\
\hline Psychological stress, $n$ (\%) & $14,306(24)$ & $4306(30)$ & $3560(25)$ & $3505(25)$ & $1726(12)$ & $1209(8)$ \\
\hline \multicolumn{7}{|l|}{ Parity } \\
\hline None, $n(\%)$ & $28,325(47)$ & $5920(21)$ & $6600(23)$ & $10,210(36)$ & $3664(13)$ & $1931(7)$ \\
\hline$\geq 1, n(\%)$ & $31,810(53)$ & $3427(11)$ & $6876(22)$ & $12,976(41)$ & $5354(17)$ & $3177(10)$ \\
\hline Oral contraceptive use, $n(\%)$ & $417(1)$ & $115(28)$ & $113(27)$ & $102(24)$ & $44(11)$ & $43(10)$ \\
\hline Family history of hypertension, $n(\%)$ & $95(0)$ & $28(29)$ & $23(24)$ & $28(29)$ & $10(11)$ & $6(6)$ \\
\hline Diabetes, $n(\%)$ & $809(1)$ & $157(19)$ & $187(23)$ & $274(34)$ & $115(14)$ & $76(9)$ \\
\hline Hypertension, $n$ (\%) & $1798(3)$ & $412(23)$ & $414(23)$ & $541(30)$ & $241(13)$ & $190(11)$ \\
\hline
\end{tabular}

$B M I$ body mass index, SBP systolic blood pressure, DBP diastolic blood pressure, oral contraceptive use was defined as current or ever use

satisfaction and stress by measurement of 40 items regarding stressors and job satisfaction on a 6-point Likert-type scale. The questionnaires captured the degree of stress from "none", "low", and "high" and we dichotomised as yes (high or low) or no (none) for the analysis. Both of questionnaires were validated and widely utilised in China and as well as across the world. The questionnaires were built to identify the psychological stress of the participants in the preceding 10 years.

Participants were categorised by cigarette smoking behaviours as non-smokers (including ex-smokers) and current smokers, and also by passive smoking status into non-passive smokers and passive smokers. Alcohol drinking behaviours were categorised into non-drinkers and current drinkers. Imbalanced diet was defined as that which predominantly or wholly involved consumption of one of vegetables, eggs or meats.

\section{Ascertainment of clinical measurements}

Blood pressure (BP) was measured twice in the upper left arm after 5-10 min of rest in a seated position using an automated device (HBP-9021 J, Omron, Japan). The mean of these two measurements was used for further analysis. Hypertension was classified by physicians according to history of diagnosed hypertension, use of blood pressure medication or measured systolic blood pressure (SBP) $\geq 140 \mathrm{mmHg}$ and/or diastolic blood pressure (DBP) $\geq 90 \mathrm{mmHg}$ according to criterion of the JNC 


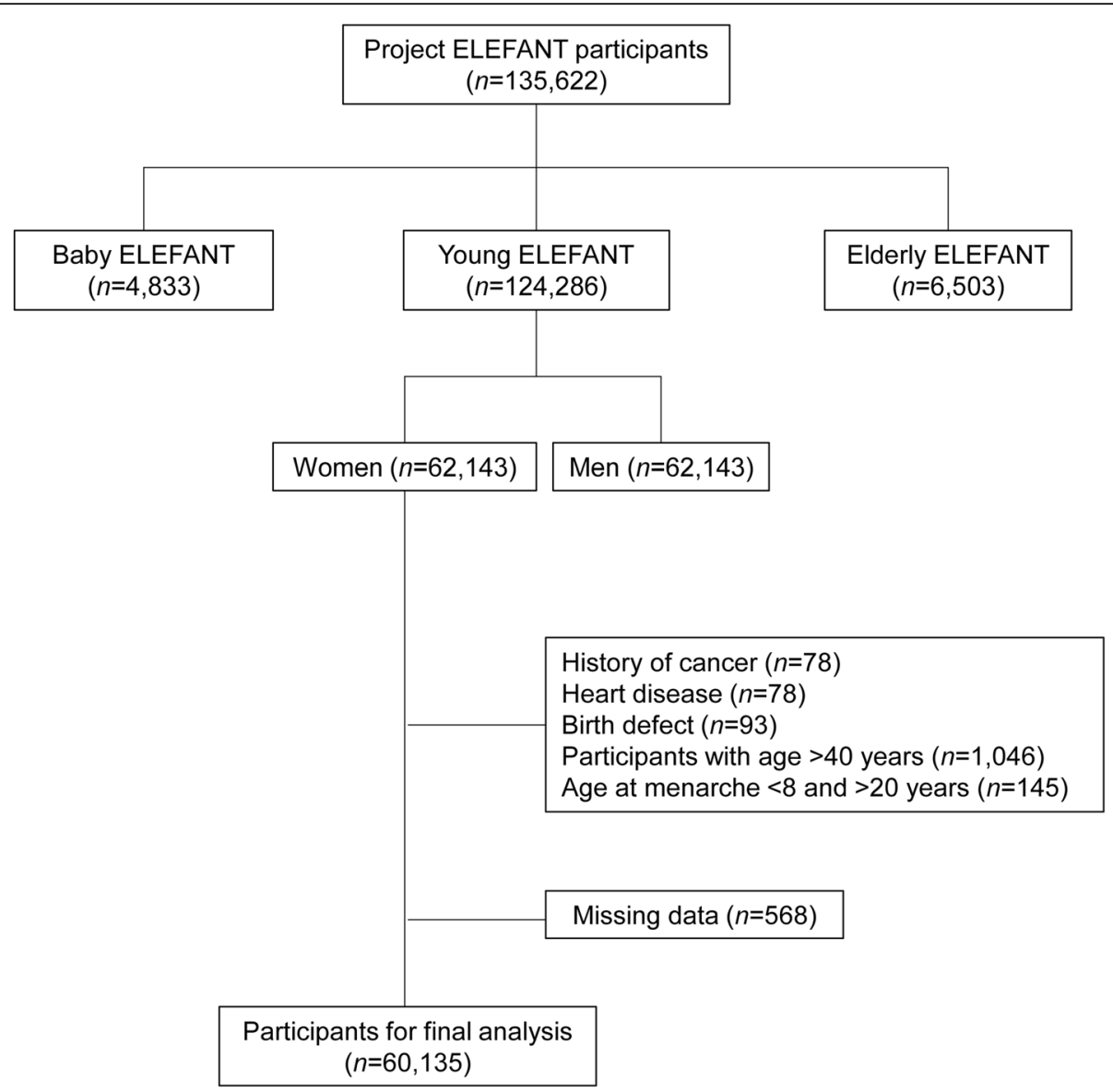

Fig. 1 Participant selection flow chart for the study

7 (Seventh Report of the Joint National Committee on Prevention, Detection, Evaluation, and Treatment of High Blood Pressure) [9].

BMI was calculated as weight divided by height squared $\left(\mathrm{kg} / \mathrm{m}^{2}\right)$, measured at local hospitals. Based on the Department of Disease Control Ministry of Health People's Republic of China (PRC), we considered participants with a BMI below 24 as normal weight, between 24 and 28 as overweight, and a BMI higher than 28 as obese [16].

\section{Statistical analysis}

Multivariable logistic regression analyses were performed to estimate odds ratios (ORs) and 95\% confidence intervals (CIs) for hypertension in relation to age at menarche (categorised into $\leq 12,13,14,15, \geq 16$ years, with 14 years of age as the reference group) and unhealthy lifestyles (BMI, psychological stress, smoking status, passive smoking status, and imbalanced diet) separately. To determine whether potential confounders could affect the ORs for hypertension by age at menarche, we used a multivariable logistic regression model adjusting for age at enrolment, smoking status, passive smoking status, drinking status, education, occupation, region, psychological stress, diabetes, family history of hypertension and other reproductive characteristics including parity, and oral contraceptive use. The separate multivariable logistic models for the relation between hypertension and unhealthy lifestyles were adjusted for age at enrolment, education, occupation, region, diabetes, family history of hypertension, parity, and oral contraceptive use and other unhealthy lifestyles.

The combined association of age at menarche and any one of the unhealthy lifestyles was assessed by including categorical variables for both hypertension and the lifestyle factor and including the interaction between the two categorical variables into the regression model. Multivariable logistic regressions were performed to analyse the associations between those combined associations and hypertension adjusting for age at enrolment, education, occupation, region, diabetes, family history of hypertension, parity, and oral contraceptive use and other unhealthy lifestyles. Multiplicative interactions between age at menarche and traditional risk factor categories was examined by inputting the product interaction terms in the logistic regression model adjusting for the above potential confounders using the likelihood ratio test. 
To examine the joint effect of multiple of modifiable risk factors and age at menarche on hypertension, we categorised the each modifiable risk factor into two groups, low or high, and created a composite variable specified as the number of high risk factors an individual had. For example, the lowest risk group was defined as those with uniformly healthy lifestyles - none of these risk factors. The highest risk group was those who exclusively had the unhealthy lifestyle characteristics and were thus categorised as high risk for all four modifiable risk factors. Multivariable logistic regressions were performed to analyse the joint effects of age at menarche and combinations of modifiable risk factors adjusting for age at enrolment, education, occupation, region, diabetes, family history of hypertension, parity, and oral contraceptive use. Multiplicative interactions between age at menarche and combinations of modifiable risk factors were also examined by inputting the product interaction terms in the logistic regression model adjusting for the above potential confounders using the likelihood ratio test. Bivariate and multivariate analysis was conducted and statistical significance was defined $p$-value $<0.05$. All statistical analyses were performed using the SAS software program (version 9.4).

\section{Results}

\section{Basic characteristic of participants}

The ages of the Young ELEFANT participants in this study were between 24 and 40-years-old (mean age: 29-year-old, SD 4.12). The mean BMI was $22.53 \mathrm{~kg} / \mathrm{m}^{2}$ (SD 3.85), with $19 \%$ of the participants $(11,623)$ classified as overweight and 7\% (4252) as obese. Overall, 7\% of participants were current alcohol drinkers, $1 \%$ were smokers and $25 \%$ were exposed to second-hand smoking. The majority of participants maintained a balanced diet and only $2 \%$ were on an imbalanced diet. Further, $44 \%$ of participants were highly educated ( $\geq 16$ years of schooling), more than $98 \%$ were employed, $24 \%$ of the participants experienced at least one of work-related, social or financial stress, and 3\% participants were classified as hypertensive. For menarche age, $16 \%$ (9347) of the young female participants had menarche at age $\leq 12,22 \%$ at age $13,39 \%$ at age $14,15 \%$ at age 15 and $8 \%$ at age $\geq 16$ (Table 1 ).

\section{Hypertension risk by menarche age and lifestyles}

To understand the risk of hypertension in young adults, we calculated ORs for hypertension by each age at menarche group. The ORs of hypertension showed a U-shaped distribution, with the highest ORs observed in women with age at menarche of $\leq 12$ (OR $=1.47,95 \%$ CI: $1.28,1.70)$ and $\geq 16(\mathrm{OR}=1.37,95 \% \mathrm{CI}: 1.16,1.64)$ (Fig. 2 and Additional file 1). The analysis was adjusted for age at enrolment, smoking status, passive smoking status, drinking status, education, occupation, residential region, psychological stress, diabetes, family history of hypertension and reproductive characteristics including parity, and oral contraceptive use.

We next examined whether ORs of hypertension were associated with lifestyles during their young adult life (Table 2). Among young women, higher ORs of hypertension were associated with high BMI (overweight: $\mathrm{OR}=2.63,95 \% \mathrm{CI}: 2.35,2.96$ and obese: $\mathrm{OR}=6.50$, 95\% CI: 5.72, 7.37), psychological stress $(\mathrm{OR}=1.38$, 95\% CI: $1.21,1.57)$, passive smoking ( $\mathrm{OR}=1.55,95 \%$ CI: $1.37,1.75)$ and imbalanced diet $(\mathrm{OR}=1.25,95 \%$ CI: 1.02, 1.72). Active smoking behaviour was not associated with hypertension $(\mathrm{OR}=1.00,95 \% \mathrm{CI}$ : 0.70 ,

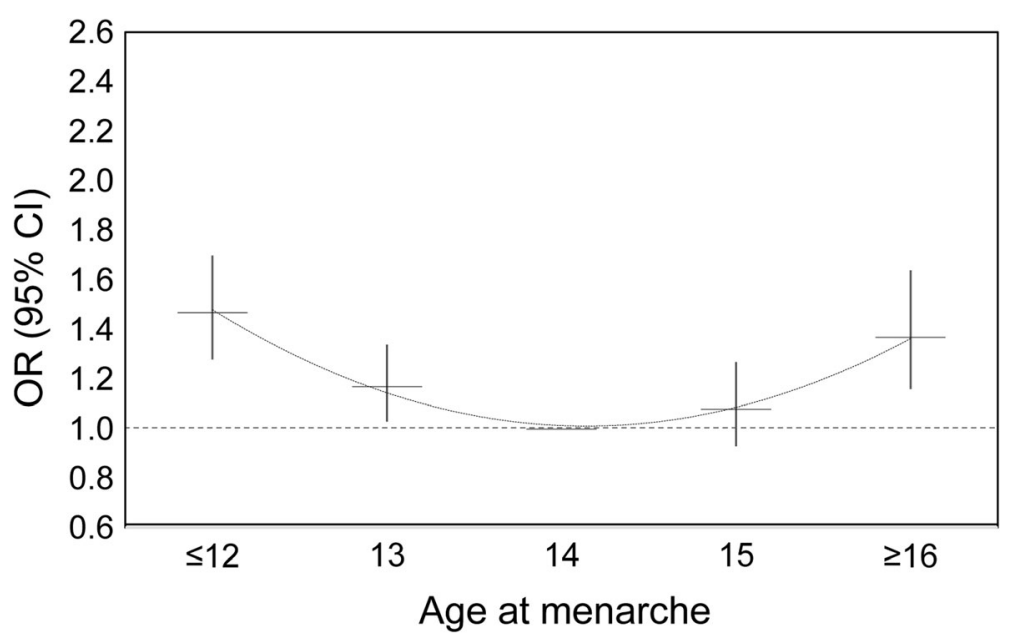

Fig. 2 Odds ratios (95\% Cls) for hypertension by category of age at menarche among young women. The model was adjusted for age at enrolment, smoking status, passive smoking status, drinking status, imbalanced diet, education, occupation, region, psychological stress, parity, oral contraceptive use, diabetes, and family history of hypertension 
Table 2 Odds ratios (95\% Cls) for hypertension among young women by lifestyles

\begin{tabular}{lllll}
\hline Lifestyle & Participants $(n)$ & Hypertension $(n)$ & OR & $95 \% \mathrm{Cl}$ \\
\hline BMl & & & & \\
Normal weight & 43,539 & 739 & 1.00 & Ref \\
Overweight & 11,613 & 553 & 2.63 & $2.35,2.96$ \\
Obesity & 4244 & 506 & 6.50 & $5.72,7.37$ \\
Psychological stress & & & \\
No & 45,829 & 1122 & 1.00 & Ref \\
Yes & 14,306 & 676 & 1.38 & $1.21,1.57$ \\
Passive smoking & & & & \\
No & 45,243 & 1081 & 1.00 & Ref \\
Yes & 14,892 & 717 & 1.55 & $1.37,1.75$ \\
Smoke & & & & \\
No & 59,361 & 1749 & 1.00 & Ref \\
Yes & 774 & 49 & 1.00 & $0.70,1.35$ \\
Imbalanced diet & & & & \\
No & 58,785 & 1729 & 1.00 & Ref \\
Yes & 1350 & 69 & 1.25 & $1.02,1.72$ \\
\hline
\end{tabular}

Odds ratios were adjusted for age at enrolment, drinking status, education, occupation, region, parity, oral contraceptive use, diabetes, family history of hypertension, age at menarche and each other lifestyle
1.35). All analyses were adjusted for age at enrolment, drinking status, education, occupation, region, parity, oral contraceptive use, diabetes, family history of hypertension, age at menarche and each other lifestyle.

Joint effects between age at menarche and lifestyles on hypertension revealed that there was interaction between participants with age at menarche $\leq 12$ and being overweight $\left(P_{\text {interaction }}=0.005\right)$ or obese $\left(P_{\text {interaction }}<0.001\right)$ (Fig. 3 and Additional file 2). There were no interactions between age at menarche with other lifestyles (Fig. 3 and Additional files 3, 4 and 5).

\section{Hypertension risk by combination of modifiable risk factors with age at menarche}

Each lifestyle risk factor independently displayed an association with age at menarche in the risk of hypertension. To examine how the combined associations of lifestyle risk factors and age at menarche may increase the risk of hypertension, we categorised patients by the sum of high-risk lifestyle factors. For example, the lowest risk group were defined as those with healthy weight, no psychological stress, not exposed to passive smoking, and maintained a balance diet, which accounted for $49.46 \%$ of the study population. The highest risk group comprised participants who were overweight or obese, reported psychological stress, exposed to passive
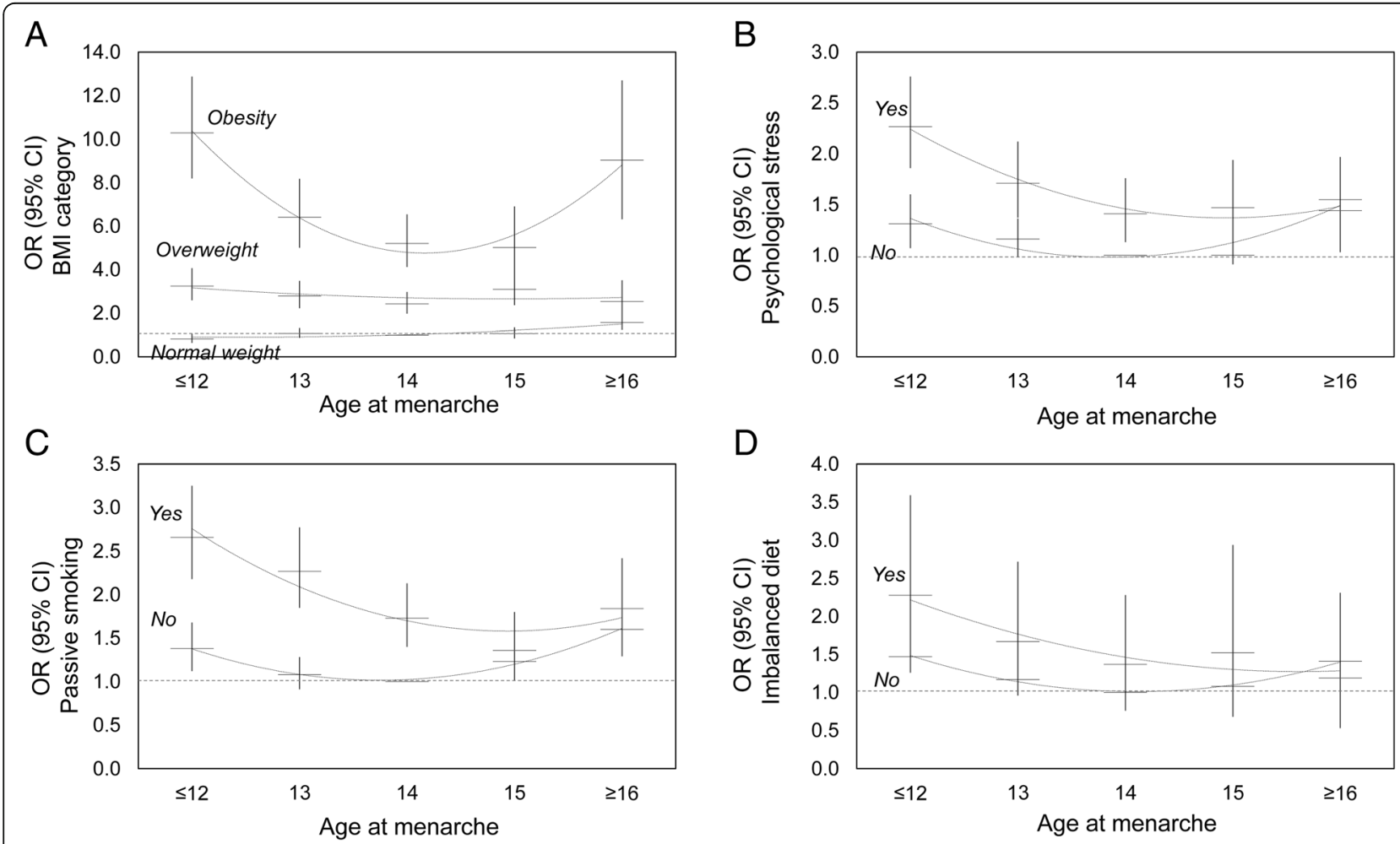

Fig. 3 Odds ratios (95\% Cls) for hypertension by age at menarche with lifestyles. The analyses were adjusted for age at enrolment, drinking status, education, occupation, region, parity, oral contraceptive use, diabetes, family history of hypertension, age at menarche and each other lifestyle 
smoking and had an imbalanced diet, which corresponded to $0.17 \%$ of the study population. We observed that late menarche age $(\geq 16)$ alone was still associated with increased risk of hypertension ( $\mathrm{OR}=2.07,95 \%$ CI: 1.54, 2.76) in participants with none of the high-risk lifestyles (Table 3). The risk of hypertension increased with greater numbers of high risk lifestyles, particularly among individuals with menarche at age $\leq 12$, ranging from 0.53 (95\% CI: $0.31,0.84$ ) in the lowest risk group to 13.21 (95\% CI: 5.17, 29.36) in the highest risk group. The risk of hypertension among individuals with menarche age of 14 increased from 1.00 (reference) in the lowest risk group to 7.13 (95\% CI: 1.13, 24.8) in the highest risk group (Table 3).

\section{Discussion}

Our analysis of a large cohort of young adult Chinese women revealed that both early and late age at menarche are associated with the risk of hypertension. Among lifestyles known to be risk factors for hypertension, BMI showed interaction with age at menarche. To the best of our knowledge, our study is the first to demonstrate that the risk of hypertension in a vulnerable population, that is young adult women with menarche age of $\leq 12$ or $\geq 16$, is substantially increased among women with other key risk factors (higher BMI, psychological stress, passive smoking and an imbalanced diet). This finding suggests that the risk of hypertension in this population could be mitigated through lifestyle modification, and thereby provides huge public health, societal and economic benefit.

High blood pressure increases the risk of many other conditions, including heart disease, heart attacks, strokes, heart failure, kidney disease and vascular dementia. Risk factors for hypertension include age, being overweight or obese, dietary habits (e.g. high consumption of salt, alcohol or coffee and lower intake of vegetables), sedentary

Table 3 Odds ratios (95\% Cls) for hypertension related to age at menarche by different combinations of modifiable risk lifestyles among young women

\begin{tabular}{|c|c|c|c|c|c|}
\hline \multicolumn{2}{|l|}{ Joint Exposure } & \multirow[b]{2}{*}{ Total $(n)$} & \multicolumn{2}{|c|}{ Hypertension } & \multirow[b]{2}{*}{$95 \% \mathrm{Cl}$} \\
\hline Age at menarche (years) & Modifiable risk lifestyles & & $\bar{n}$ & OR & \\
\hline$\leq 12$ & No risk lifestyles & 2747 & 18 & 0.53 & $0.31,0.84$ \\
\hline 13 & & 6113 & 89 & 1.07 & $0.83,1.39$ \\
\hline 14 & & 13,216 & 181 & 1.00 & Ref \\
\hline 15 & & 4640 & 72 & 1.11 & $0.84,1.46$ \\
\hline$\geq 16$ & & 2139 & 63 & 2.07 & $1.54,2.76$ \\
\hline$\leq 12$ & One risk lifestyle & 2582 & 90 & 2.76 & $2.09,3.60$ \\
\hline 13 & & 4001 & 125 & 2.25 & $1.78,2.85$ \\
\hline 14 & & 6667 & 207 & 2.16 & $1.76,2.66$ \\
\hline 15 & & 2733 & 98 & 2.51 & $1.95,3.22$ \\
\hline$\geq 16$ & & 1701 & 61 & 2.54 & $1.87,3.41$ \\
\hline$\leq 12$ & Two risk lifestyles & 2656 & 156 & 5.24 & $4.11,6.69$ \\
\hline 13 & & 2347 & 113 & 3.98 & $3.07,5.14$ \\
\hline 14 & & 2212 & 92 & 3.32 & $2.54,4.33$ \\
\hline 15 & & 1180 & 48 & 3.18 & $2.24,4.41$ \\
\hline$\geq 16$ & & 897 & 47 & 3.81 & $2.67,5.32$ \\
\hline$\leq 12$ & Three risk lifestyles & 910 & 141 & 12.36 & $9.51,16.05$ \\
\hline 13 & & 580 & 84 & 11.09 & $8.21,14.87$ \\
\hline 14 & & 527 & 59 & 8.62 & $6.20,11.85$ \\
\hline 15 & & 219 & 22 & 7.20 & $4.35,11.40$ \\
\hline$\geq 16$ & & 172 & 18 & 7.64 & $4.39,12.57$ \\
\hline$\leq 12$ & All four risk lifestyles & 40 & 7 & 13.21 & $5.17,29.36$ \\
\hline 13 & & 21 & 3 & 9.45 & $2.16,29.08$ \\
\hline 14 & & 23 & 2 & 7.13 & $1.13,24.80$ \\
\hline 15 & & 5 & 1 & 12.23 & $0.61,83.43$ \\
\hline$\geq 16$ & & 9 & 1 & 6.49 & $0.35,36.53$ \\
\hline
\end{tabular}

Modifiable risk lifestyles comprised being overweight or obese, psychological stress, passive smoking, and imbalanced diet. The model was adjusted for age at enrolment, smoking status, drinking status, education, occupation, region, parity, oral contraceptive use, diabetes, and family history of hypertension 
lifestyle, and insufficient sleep. In this study, passive smoking was associated with prevalence of hypertension in young adult women, but not with active smoking. For cultural reasons, active smoking may have been underreported in this cohort of young Chinese women, which may therefore serve to explain the apparent absence of an association with hypertension in our study [17]. The risk of hypertension is therefore modifiable by adopting healthy lifestyles, although there are also inherited risk factors, including sex, ethnicity and family history of the disease. It is not yet clear whether those individuals inheriting such risk factors could substantially benefit in reducing their risk of hypertension through lifestyle changes.

Early age at menarche has been shown to be associated with increased risk of hypertension in middle-aged and elderly Western women, and an association between late age at menarche and hypertension or other cardiovascular disease was recently reported in a large UK cohort [7, 18]. In this ELEFANT study, we similarly observed that young Chinese women with either early or late menarche age are at increased risk of developing hypertension. The pathophysiology underlying this association has not been elucidated, but may be related to obesity later in life. Early age at menarche is associated with increased adiposity in adulthood independent of childhood BMI, and especially with increased BMI in adult women below the age of 40 [19]. Our study examined the risk of hypertension among women under 40 and revealed this to be particularly high among obese women with early menarche, thereby identifying a population who could benefit from intervention strategies to reduce CVD incidence. In contrast, as later age at menarche is associated with lower BMI later in life [20], its association with hypertension may be through alternative mechanisms. One such possibility is through reduced exposure to oestrogen, which can reduce blood pressure through stimulation of endothelial nitric oxide synthase [21], although there is conflicting evidence for the effect of oestrogen upon blood pressure [22].

Young adults with even mildly higher blood pressure display increased incidence of heart disease in later life [23]. However, known as a "silent killer", undiagnosed hypertension is common especially in young adults [24]. Within our cohort, $90 \%$ of participants meeting the criteria for hypertension diagnosis had not been previously diagnosed (Additional file 6). Our study has revealed that early and late menarche age are associated with the development of hypertension in young adults. This finding has important implications, as the early detection of hypertension and maintenance of healthy blood pressure in young women with earlier and later menarche age could be critical to decrease the incidence CVD in later life.

Modification of lifestyle has been shown to impact upon lowering blood pressure and has been proposed as a non-pharmacological approach to the prevention and treatment of hypertension [25]. Many studies have focused on modification of a single lifestyle factor for prevention $[26,27]$, though results of multiple interventions, including dietary intervention with increased physical activity, have been demonstrated to be effective in reducing blood pressure in middle-aged (mean age: 50 ) men and women $[28,29]$. We report that risk of hypertension in vulnerable young adult women, those with either early or late menarche age, increases with the additive associations of multiple high-risk lifestyles. The recommendation of healthy lifestyles to those vulnerable individuals when young could be a highly potent and cost-effective means to reduce the incidence of hypertension and CVD in later life.

Our study utilised a large and well-characterised cohort, with complete information on socio-economic status, lifestyles and reproductive characteristics. All clinical and other questionnaire data measures were carefully standardised and assessed. We rigorously controlled for potential confounders to analyse the relative risk of hypertension. Further, the examination of hypertension in young adult women enabled the elucidation of the associations of menarche age on risk without potential confounding through post-menopausal effects.

Our study contains several potential limitations. The age at menarche was recalled at the time of enrolment, when the participants were young adults. However, it has been shown that the self-reported age at menarche is highly correlated with original age at menarche [30]. Secondly, childhood adiposity, which is considered a risk factor for early pubertal timing [19], was not available in this study. Thirdly, physical activity is potentially suitable as a further modifiable lifestyle factor for investigation in relation to modulation of hypertension risk, but such data was not available within the Young ELEFANT study. Finally, the collected dietary data does not include specific analysis of sodium intake, which is associated with the risk of hypertension. In addition, the classification of obesity by BMI score differs between Asian and Western populations, therefore our findings will need to be validated in a Western cohort. Finally, on account of the observational characteristic of cross-sectional studies, residual confounding by unknown factors might exist.

\section{Conclusions}

In summary, we report that early and late age of menarche are strongly associated with risk of hypertension in young adult Chinese women. Among these individuals, there was an additive association of high-risk lifestyles in increasing the risk of hypertension. Our findings suggest that modification of lifestyle, such as consumption of a balanced diet and maintenance of normal weight could substantially reduce the risk of hypertension in high-risk individuals. 


\section{Additional files}

Additional file 1: Odds ratios $(95 \% \mathrm{Cls})$ for hypertension among young women by age at menarche. (DOCX $26 \mathrm{~kb}$ )

Additional file 2: Odds ratios $(95 \% \mathrm{Cls})$ for hypertension related to age at menarche by BMI. (DOCX $27 \mathrm{~kb}$ )

Additional file 3: Odds ratios $(95 \% \mathrm{Cls})$ for hypertension related to age at menarche by psychological stress. (DOCX $26 \mathrm{~kb}$ )

Additional file 4: Odds ratios $(95 \% \mathrm{Cls})$ for hypertension related to age at menarche by passive smoking. (DOCX $26 \mathrm{~kb}$ )

Additional file 5: Odds ratios $(95 \% \mathrm{Cls})$ for hypertension related to age at menarche by imbalanced diet. (DOCX $27 \mathrm{~kb}$ )

Additional file 6: Distribution of age and BMI among undiagnosed hypertension $(n=1654)$ and diagnosed hypertension $(n=144)$ in Young ELEFANT. (DOCX $25 \mathrm{~kb}$ )

\section{Abbreviations}

BP: Blood pressure; Cis: confidence intervals; CVD: cardiovascular disease; DBP: diastolic blood pressure; ELEFANT: Environmental and LifEstyle FActors iN metabolic health throughout life-course Trajectories; ORs: odds ratios; SBP: systolic blood pressure

\section{Acknowledgments}

We would like to thank all participants within Project ELEFANT study in Tianjin city, China. We are also extremely grateful to all the hospital staff and researchers involved in data collection, particularly Xiqing Hospital, Tianjin Research Institute for Family Planning and Junliangcheng Hospital. We are extremely grateful to all our collaborators for their support in establishing this study.

\section{Funding}

This work was supported in part by National Natural Science Foundation of China (Grant numbers 81602827 to LG and 41601548 to PL).

\section{Availability of data and materials}

The datasets used and/or analysed during the current study are available from the corresponding author on reasonable request.

\section{Authors' contributions}

LG and HMB designed the research; CP and HX analysed the data; $A W$ and TMB interpreted the data analysis and results; TMB and HMB wrote the paper; PL, HW, LS, XQ, NT, HL, XC provided the primary data; LG had primary responsibility for final content. All authors read and approved the final manuscript. LG, CP, and HX contributed equally.

\section{Ethics approval and consent to participate}

The protocol of this study was approved by the Institutional Review Board of the Tianjin Medical University and the procedures followed were in accordance with institutional guidelines. Participants gave written informed consent prior to participation in the study.

\section{Consent for publication}

Not applicable.

\section{Competing interests}

The authors declare that they have no competing interests.

\section{Publisher's Note}

Springer Nature remains neutral with regard to jurisdictional claims in published maps and institutional affiliations.

\section{Author details}

'Department of Occupational \& Environmental Health, School of Public Health, Tianjin Medical University, 22nd Qixiangtai Road, Heping District, Tianjin 300070, China. ${ }^{2}$ Department of Environmental Health, Harvard T.H. Chan School of Public Health, Boston, MA, USA. ${ }^{3}$ Department of Epidemiology and Statistics, School of Public Health, Tianjin Medical University, Tianjin, China. ${ }^{4}$ Department of Statistics, Colorado State University, Fort Collins, CO, USA. ${ }^{5}$ School of Environmental Science and Safety
Engineering, Tianjin University of Technology, Tianjin, China. ${ }^{6}$ Tianjin Research Institute for Family Planning, Tianjin, China. ${ }^{7}$ Faculty of Health Sciences and Wellbeing, University of Sunderland, Sunderland, UK. ${ }^{8}$ Human Nutrition Research Centre, Institute of Cellular Medicine, Newcastle University, Newcastle upon Tyne, UK.

Received: 27 June 2018 Accepted: 28 October 2018

Published online: 09 November 2018

\section{References}

1. Graber JA, Brooks-Gunn J, Warren MP. The antecedents of menarcheal age: heredity, family environment, and stressful life events. Child Dev. 1995;66: 346-59.

2. Dvornyk V, Waqar ul H. Genetics of age at menarche: a systematic review. Hum Reprod Update. 2012;18:198-210.

3. Karapanou O, Papadimitriou A. Determinants of menarche. Reprod Biol Endocrinol. 2010:8:115

4. Delahanty RJ, Beeghly-Fadiel A, Long JR, Gao YT, Lu W, Xiang YB, Zheng Y, Ji BT, Wen WQ, Cai QY, et al. Evaluation of GWAS-identified genetic variants for age at menarche among Chinese women. Hum Reprod. 2013:28:1135-43.

5. Velez Edwards DR, Baird DD, Hartmann KE. Association of age at menarche with increasing number of fibroids in a cohort of women who underwent standardized ultrasound assessment. Am J Epidemiol. 2013;178:426-33.

6. Elks CE, Ong KK, Scott RA, van der Schouw YT, Brand JS, Wark PA, Amiano P, Balkau B, Barricarte A, Boeing $H$, et al. Age at menarche and type 2 diabetes risk: the EPIC-InterAct study. Diabetes Care. 2013;36:3526-34.

7. Canoy D, Beral V, Balkwill A, Wright FL, Kroll ME, Reeves GK, Green J, Cairns BJ, Million Women Study C. Age at menarche and risks of coronary heart and other vascular diseases in a large UK cohort. Circulation. 2015;131:237-44.

8. Wenger NK. Juggling multiple guidelines: a Woman's heart in the balance. J Women's Health (Larchmt). 2016;25:213-21.

9. Chobanian AV, Bakris GL, Black HR, Cushman WC, Green LA, Izzo JL Jr, Jones DW, Materson BJ, Oparil S, Wright JT Jr, et al. The Seventh Report of the Joint National Committee on Prevention, Detection, Evaluation, and Treatment of High Blood Pressure: the JNC 7 report. JAMA. 2003:289:2560-72.

10. Ewald DR, Haldeman Ph DL. Risk factors in adolescent hypertension. Glob Pediatr Health. 2016:3:2333794×15625159.

11. Whelton PK, He J, Appel LJ, Cutler JA, Havas S, Kotchen TA, Roccella EJ, Stout R, Vallbona C, Winston MC, et al. Primary prevention of hypertension: clinical and public health advisory from The National High Blood Pressure Education Program. JAMA. 2002;288:1882-8.

12. Barrow TM, Peng C, Wilson A, Wang H, Liu H, Shen L, Tang NJ, Sae-Lee C, Li $\mathrm{PH}$, Guo L, Byun HM. Psychosocial stress is associated with benign breast disease in young Chinese women: results from project ELEFANT. Breast Cancer Res Treat. 2018. https://doi.org/10.1007/s10549-018-4979-4.

13. Meng X, Li S, Duan W, Sun Y, Jia C. Secular trend of age at menarche in Chinese adolescents born from 1973 to 2004. Pediatrics. 2017;140:e20170085.

14. Siu O, Donald I, Cooper CL. The use of the occupational stress indicator (OSI) in factory workers in China. Int J Stress Manage. 1997:4:171-82.

15. Cohen S, Kamarck T, Mermelstein R. A global measure of perceived stress. J Health Soc Behav. 1983;24:385-96.

16. Chen C, Lu FC. Department of Disease Control Ministry of health PRC: the guidelines for prevention and control of overweight and obesity in Chinese adults. Biomed Environ Sci. 2004:17(Suppl):1-36.

17. Yang Y, Liu F, Wang L, Li Q, Wang X, Chen JC, Wang Q, Shen H, Zhang Y, Yan D, et al. Association of Husband Smoking with Wife's hypertension status in over 5 million Chinese females aged 20 to 49 years. J Am Heart Assoc. 2017;6:e004924.

18. Lakshman R, Forouhi NG, Sharp SJ, Luben R, Bingham SA, Khaw KT, Wareham NJ, Ong KK. Early age at menarche associated with cardiovascular disease and mortality. J Clin Endocrinol Metab. 2009;94:4953-60.

19. Prentice $P$, Viner RM. Pubertal timing and adult obesity and cardiometabolic risk in women and men: a systematic review and meta-analysis. Int J Obes. 2013;37:1036-43.

20. Liu G, Yang Y, Huang W, Zhang N, Zhang F, Li G, Lei H. Association of age at menarche with obesity and hypertension among southwestern Chinese women: a new finding. Menopause. 2018:25:546.

21. Chen Z, Yuhanna IS, Galcheva-Gargova Z, Karas RH, Mendelsohn ME, Shaul PW. Estrogen receptor alpha mediates the nongenomic activation of endothelial nitric oxide synthase by estrogen. J Clin Invest. 1999;103:401-6. 
22. Dubey RK, Oparil S, Imthurn B, Jackson EK. Sex hormones and hypertension. Cardiovasc Res. 2002;53:688-708.

23. Kishi S, Teixido-Tura G, Ning H, Venkatesh BA, Wu C, Almeida A, Choi EY, Gjesdal $\mathrm{O}$, Jacobs DR Jr, Schreiner PJ, et al. Cumulative blood pressure in early adulthood and cardiac dysfunction in middle age. The CARDIA Study J Am Coll Cardiol. 2015;65:2679-87.

24. Johnson HM, Thorpe CT, Bartels CM, Schumacher JR, Palta M, Pandhi N, Sheehy AM, Smith MA. Undiagnosed hypertension among young adults with regular primary care use. J Hypertens. 2014;32:65-74.

25. Li J, Zheng H, Du HB, Tian XP, Jiang YJ, Zhang SL, Kang Y, Li X, Chen J, Lu C, et al. The multiple lifestyle modification for patients with prehypertension and hypertension patients: a systematic review protocol. BMJ Open. 2014;4:e004920.

26. He FJ, MacGregor GA. Effect of modest salt reduction on blood pressure: a meta-analysis of randomized trials. Implications for public health. J Hum Hypertens. 2002;16:761-70.

27. Whelton SP, Chin A, Xin X, He J. Effect of aerobic exercise on blood pressure: a meta-analysis of randomized, controlled trials. Ann Intern Med. 2002;136:493-503.

28. Nicoll R, Henein MY. Hypertension and lifestyle modification: how useful are the guidelines? Br J Gen Pract. 2010;60:879-80.

29. Svetkey LP, Erlinger TP, Vollmer WM, Feldstein A, Cooper LS, Appel $\sqcup$, Ard JD, Elmer PJ, Harsha D, Stevens VJ. Effect of lifestyle modifications on blood pressure by race, sex, hypertension status, and age. J Hum Hypertens. 2005;19:21-31.

30. Must A, Phillips SM, Naumova EN, Blum M, Harris S, Dawson-Hughes B, Rand WM. Recall of early menstrual history and menarcheal body size: after 30 years, how well do women remember? Am J Epidemiol. 2002;155:672-9.

Ready to submit your research? Choose BMC and benefit from:

- fast, convenient online submission

- thorough peer review by experienced researchers in your field

- rapid publication on acceptance

- support for research data, including large and complex data types

- gold Open Access which fosters wider collaboration and increased citations

- maximum visibility for your research: over $100 \mathrm{M}$ website views per year

At $\mathrm{BMC}$, research is always in progress.

Learn more biomedcentral.com/submissions 